Fourth Annual

1992 International Industr1al Symposium

on the Super Coll1der (IISSC)

New Orleans, Loulstana

March 4-6, 1992

\title{
A PRECISE TECHNIQUE FOR MANUFACTURING CORRECTION COIL*
}

\section{Leonard Schieber}

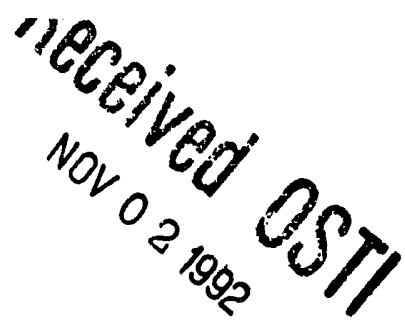

Accelerator Development Department

Magnet Division

Brookhaven National Laboratory

Magnet Division - Bldg. 902A

Upton, New York 11973

\section{INTRODUCTION}

An automated method of manufacturing correction coils has been developed which provides a precise embodiment of the coil design. Numerically controlled machine have been developed to accurately position coil windings on the beam tube. Two types of machines have been built. One machine bonds the wire to a substrate which is wrapped around the beam tube after it is completed while the second machine bonds the wire directly to the beam tube. Both machines use the Multiwire technique of bonding the wire to the substrate utilizing an ultrasonic stylus. These machines are being used to manufacture coils for both the SSC and RHIC.

\section{DIRECT WINDNG TECHNIQUE}

An automated method of manufacturing correction coils directly on the beam tube has been developed for the SSCL. The direct winding technique utilizes a mumerically controlled wiring machine consisting of a moveable wiring bead positioned above a mandrel which holds the beam tube. A servo positions the wiring head along a track mounted on a bridge above the mandrel. The bead has a travel of approximately 70". The head assembly contains a mechanism to control the feed rate of the wire, an ultrasonic stylus to bond the wire to the tube, a coil to excite the stylus and a servo system to rotate the stylus about its vertical axis.

The mandrel is mounted below the wiring head on a granite table. The beam tube is chucked into the mandrel much like the work in a turning lathe. A servo rotates the beam tube in response to commands from the computer.

"Work supported by the U.S. Department of Energy

\section{DISCLAIMER}

This report was prepared as an account of work sponsored by an agency of the United States Government. Neither the United States Government nor any agency thereof, nor any of their employees, makes any warranty, express or implied, or assumes any legal liability or responsibility for the accuracy, completeness, or usefulness of any information, apparatus, product, or process disclosed, or represents that its use would not infringe privately owned rights. Reference herein to any specific commercial product, process, or service by trade name, trader.sark, manufacturer, or otherwise does not necessarily constitute or imply its endorsement, recommendation, or favoring by the United States Government or any agency thereof. The views and opinions of authors expressed herein do not necessarily state or reflect those of the 
The desired wiring pattern is programmed on a floppy disk. The machine reads the disk and drives the servos controlling the mandrel rotation, the head rotation and the head translation along the mandrel; to trace out the pattern of the coil on the beam tube. A servo controlled feed mechanism dispenses wire at the same speed that the head is moving over the beam tube. The wire is fed under the ultrasonic stylus which is being heated in response to signals applied to the ultrasonic coil. This melts a thermosetting adhesive which has been placed on the bear tube; bonding the wire in place. Multiple layers of wire may be placed on the beam tube in this fashion.

\section{JELLYROLL TECHNIQUE}

A similar technique has been used to make correction coils for the SSC. This technique utilizes the same wiring machine by removing the Direct Wind Mandrel and replacing it with a Material Transport Mechanism. A machine set up in this configuration is shown in Figures 1 and 2 . Instead of winding the coil directly on the beam tube the coil pattern is laid on a flat substrate moved by the transport mechanism to make multiple layers. The substrate is then wrapped around the berm tube like a jellyroll. The machine shown can wind coils up to 1.2 meters wide and 8 meter long. This results in a magnet 1.2 meters in length having up to 40 layers of wires.

Figure 3 shows the Jellyroll coil on its Kapton substrate as wound by the machine. The substrate is trimmed and one end secured to the beam tube. It is then wrapped around the beam tube in the fashion of a jellyroll cake. Laminations are then clamped around the coil winding.

\section{RHIC MAGNET FACILITY}

The techniques described are also being used to make correction coils for the Relativistic Heavy Ion Collider. The RHIC design utilized individual substrates having one or two layers of wire on each substrate. The substrates are then stacked in up to six layers. Each corrector substrate is then bonded to a support tube. All support tubes are then nested to form the complete correction coil.

Figure 4 shows four of the twelve substrates used in the RHIC corrector while Figure 5 shows a close up of one of the Dipole layers. Dipole layers have two levels of wire one on top of the other. The completed coil is approximately $24^{\prime \prime}$ in length. A facility for manufacturing correction magnets for the RHIC project is being set up a the Brookhaven National Laboratory. A recent photograph of the coil winding area is shown in Figure 6. At the present time two of the machines are complete while the remaining three are in various stages of completion.

\section{SUMMARY}

The technique described has proven to be an excellent method of manufacturing correction coils. Wire placement accurate to $.004^{\prime \prime}(100 \mu \mathrm{m})$ allows precise duplication of the theoretical design. In addition, with proper construction techniques training effects are virtually eliminated. Equipment is presently available to manufacture a large variety of correction coils using this technique. 


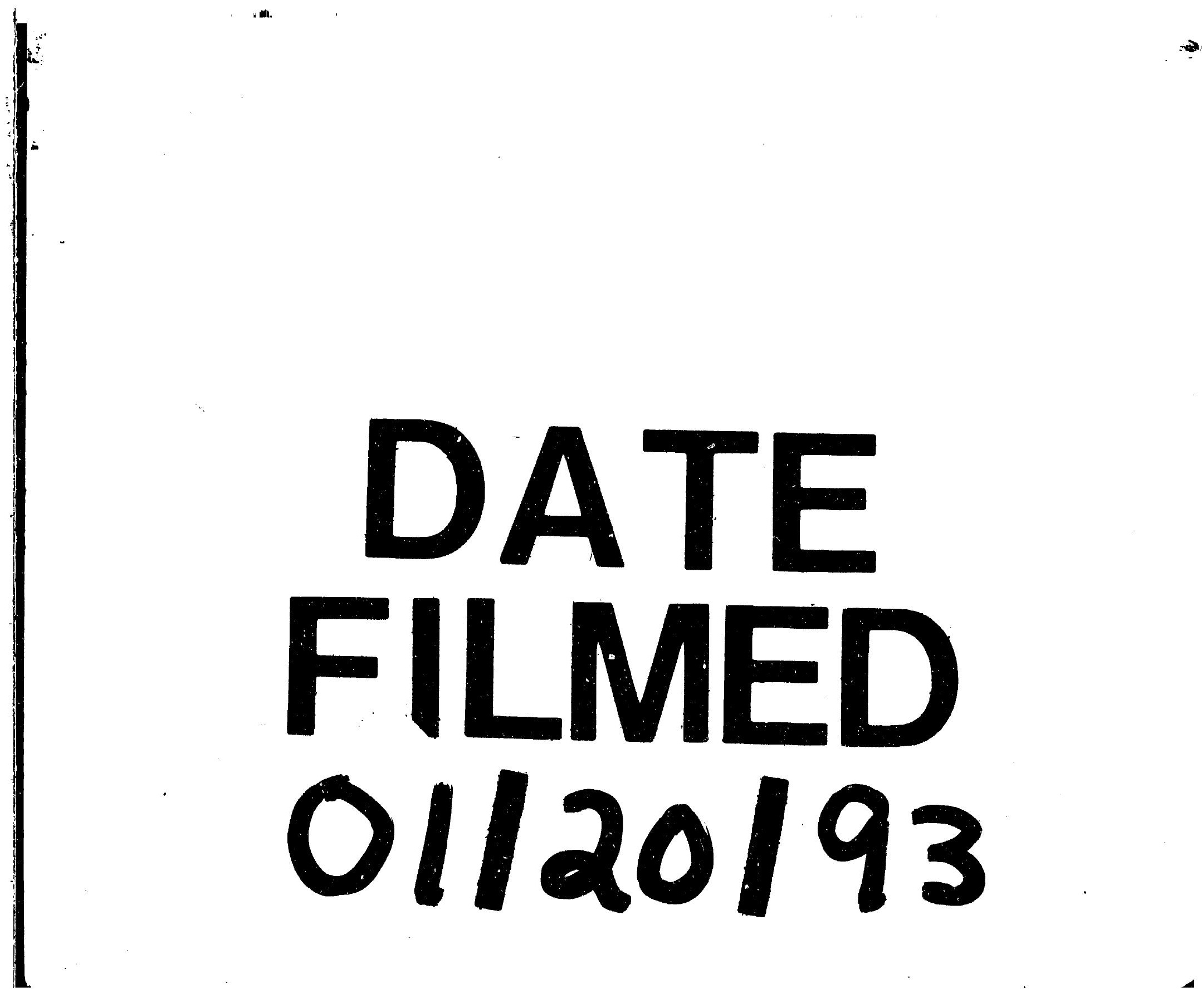


